\title{
\begin{tabular}{|lll} 
IN QUEST OF TOTAL QUALITY MANAGEMENT \\
PRINCI PLES IN ARCHITECTURAL & DESIGN \\
SERVICES: EVIDENCE FROM TURKEY &
\end{tabular} \mid
}

doi> 10.4237/gtp.v5i3.175

\author{
Umut DURMUS \\ Istanbul Technical University, Department \\ of Architecture \\ |e-mail: umutdurmus@itu.edu|
}

\author{
H. Cetin TURKCU \\ Dokuz Eylul University, Department of \\ Architecture \\ |e-mail: cetin.turkcu@deu.edu.tr|
}

\author{
H. Murat GUNAYDIN \\ Izmir Institute of Technology, Department \\ of Architecture \\ |e-mail: muratgunaydin@iyte.edu.tr|
}

\section{Emrah ACAR}

Istanbul Technical University, Department of Architecture

|e-mail: acare@itu.edu.tr

\begin{abstract}
Proposal: Architectural design companies increasingly recognize that time spent on management is not at the expense of their production and there are always better ways to organize business. Although architects have long placed a traditional emphasis on quality, quality management is still a new concept for the majority of architectural design companies, which have to organize relatively more complicated operations nowadays to meet their clients' expectations. This study aims to understand how architectural design companies define quality and explores the extent to which Total Quality Management (TQM) principles like continual improvement, employee involvement, customer satisfaction and others can be pertinent in these companies. Adopting a qualitative research strategy, the authors interviewed with the owner-managers of 10 widely-recognized architectural design companies of different size in Istanbul. The results from the content analysis of semi-structured interview data suggest that i) TQM principles cannot be directly applied in architectural design companies without an appropriate translation; ii) special characteristics of design services are important to explain quality-related perceptions of owner-managers; iii) the owner-managers feel the pressure from the changing internal and external environmental conditions, however few of them adopt a systematic and documented approach to quality management. Architectural design offices which aim to establish a quality management system can benefit from this study to understand potential problem areas on their road.
\end{abstract}

Keyw ords: Architectural Design, Total Qual ity Management, Implementation. 


\section{I NTRODUCTI ON}

As a consequence of either external pressure such as increasing quality demand of clients, or internal pressure such as organizational growth, architectural design offices seek ways to achieve higher quality targets in today's competitive markets. This is why relatively new management approaches such as Total Quality Management (TQM) are likely to be the part of the agenda of architecture companies, which aim to achieve long-term success in competitive markets through the integration of various organizational functions. TQM is based on “...all members of an organization participating in improving processes, products, services and the culture in which they work" (ASQ, 2009) to achieve organizational objectives. Saarinen and Hobel (1990) argue that TQM constituents and principles have been part of daily routines in architectural offices, although they are not always systematically described and documented as 'quality management'.

\subsection{RESEARCH PROBLEM}

Architectural design process is unique due to its nature and the designer's subjective contribution and judgement. This asserts that applying TQM principles and implementations in the architectural services sector without appropriation may not yield successful consequences, considering that TQM has its roots in the manufacturing industries. Understanding the extent to which the implementations and approaches of these offices overlap with TQM, and to which they differ remains an interesting research topic. It is important to understand how architectural design companies interpret the notions like quality, institutionalization, teamwork, leadership, continuous improvement and client satisfaction to explore better ways to enhance their productivity and quality.

\subsection{AI M AND SCOPE}

This study aims to compare the pionering architectural offices' quality perceptions and to understand the principles and methods that they adopt to create high quality outputs. The assumption was that comparing observed principles with those of TQM would generate valuable information, which could be used as input to develop an effective quality management model and which fit in with the peculiar needs of architectural design offices. For this purpose, semi-structured 
interviews were conducted with the owner-managers 10 architectural design companies in Istanbul. The sample comprised pioneering companies that are well recognized in the domestic market and appreciated in different platforms for their high standard works.

\subsection{PREVI OUS WORK}

Mayon and Mabey (1993) argue that no clear definition exists for TQM in construction firms; the process basically proceeds through the phases of planning, preparation, implementation and sustaining; and the final phase is infinite. Pheng and KeWei (1996) argue that the implementation of TQM in the construction sector is for the benefit of everyone involving in the process. Pheng and Teo (2004) explain the fallaciousness of expecting short term benefits through the necessity of cultural alternations. A rditi and Gunaydin (1997) argue that evaluating the quality on the basis of aesthetic features would give rise to controversies in consequence of subjective interpretations. Arditi and Gunaydin (1998) also underline that management participation, quality training, teamwork, customer/supplier relations and statistical methods are essential tools and elements for building projects.

Few empirical investigation exist that focus on TQM implementation in the design phase of the building production process. Majority of the studies on design and management come to the conclusion that the design process is a 'black box'. Volker and Prins (2005) argue that "it is a cognitive process in the sense that the architect is problem-solving, creating, learning, exploring; it is a social process in the sense that the architect has contact with many participants or stakeholders in a variety of relationships; it is a cultural and technical phenomenon situated in a specific cultural context; and it is a process of dealing with uncertainty and establishing useful artifacts". Sebastian (2004) highlights that all current design and project management methods have failed to penetrate the creative and subjective nature of architectural design practice, especially during the conceptual design phase. Table 1 below is a summary of TQM terminology. 


\begin{tabular}{|c|c|c|}
\hline Quality & \multicolumn{2}{|c|}{$\begin{array}{l}\text { A subjective term for which each person or sector has its own } \\
\text { definition. It may refer to the characteristics of a } \\
\text { product or servicethat bear on its ability to satisfy stated or implied } \\
\text { needs -'fitness for use' and 'conformance to requirements'; or a } \\
\text { product or servicethat is free of deficiencies (ASQ, 2009). }\end{array}$} \\
\hline $\begin{array}{l}\text { Total Quality } \\
\text { Management } \\
\text { (TQM) }\end{array}$ & \multicolumn{2}{|c|}{$\begin{array}{l}\text { A management approach to achieve long-term success through } \\
\text { customer satisfaction. TQM is based on all members of an } \\
\text { organization participating in improving processes, products, } \\
\text { services and the culture in which they work (ASQ, 2009). }\end{array}$} \\
\hline \multirow[t]{4}{*}{$\begin{array}{l}\text { TQM element } \\
\text { and principles }\end{array}$} & $\begin{array}{l}\text { Teamwork } \\
\text { and } \\
\text { employee } \\
\text { involvement }\end{array}$ & $\begin{array}{l}\text { An organizational practice whereby employees } \\
\text { regularly participate in making decisions on how } \\
\text { their work areas operate, including suggestions for } \\
\text { improvement, planning, goal setting and monitoring } \\
\text { performance (ASQ, 2009). }\end{array}$ \\
\hline & $\begin{array}{l}\text { Statistical } \\
\text { methods }\end{array}$ & $\begin{array}{l}\text { Provide teams with the tools to identify the causes of } \\
\text { quality problems, to communicate in a precise } \\
\text { language that can be understood by all team } \\
\text { members, to verify, repeat, and reproduce } \\
\text { measurements based on data, to determine the past, } \\
\text { present, and to a lesser degree, the future status of a } \\
\text { work process, and to make decisions on facts that are } \\
\text { based on data rather than the opinions and } \\
\text { preferences of individuals (Perisco, 1989). }\end{array}$ \\
\hline & $\begin{array}{l}\text { Continuous } \\
\text { improvemen }\end{array}$ & $\begin{array}{l}\text { The ongoing improvement of products, services or } \\
\text { processes through incremental and breakthrough } \\
\text { improvements (ASQ, 2009). }\end{array}$ \\
\hline & Training & $\begin{array}{l}\text { Most significant component in trying to improve } \\
\text { quality (Oakland, 1989). Under TQM, quality } \\
\text { becomes everyone's responsibility and the training }\end{array}$ \\
\hline
\end{tabular}




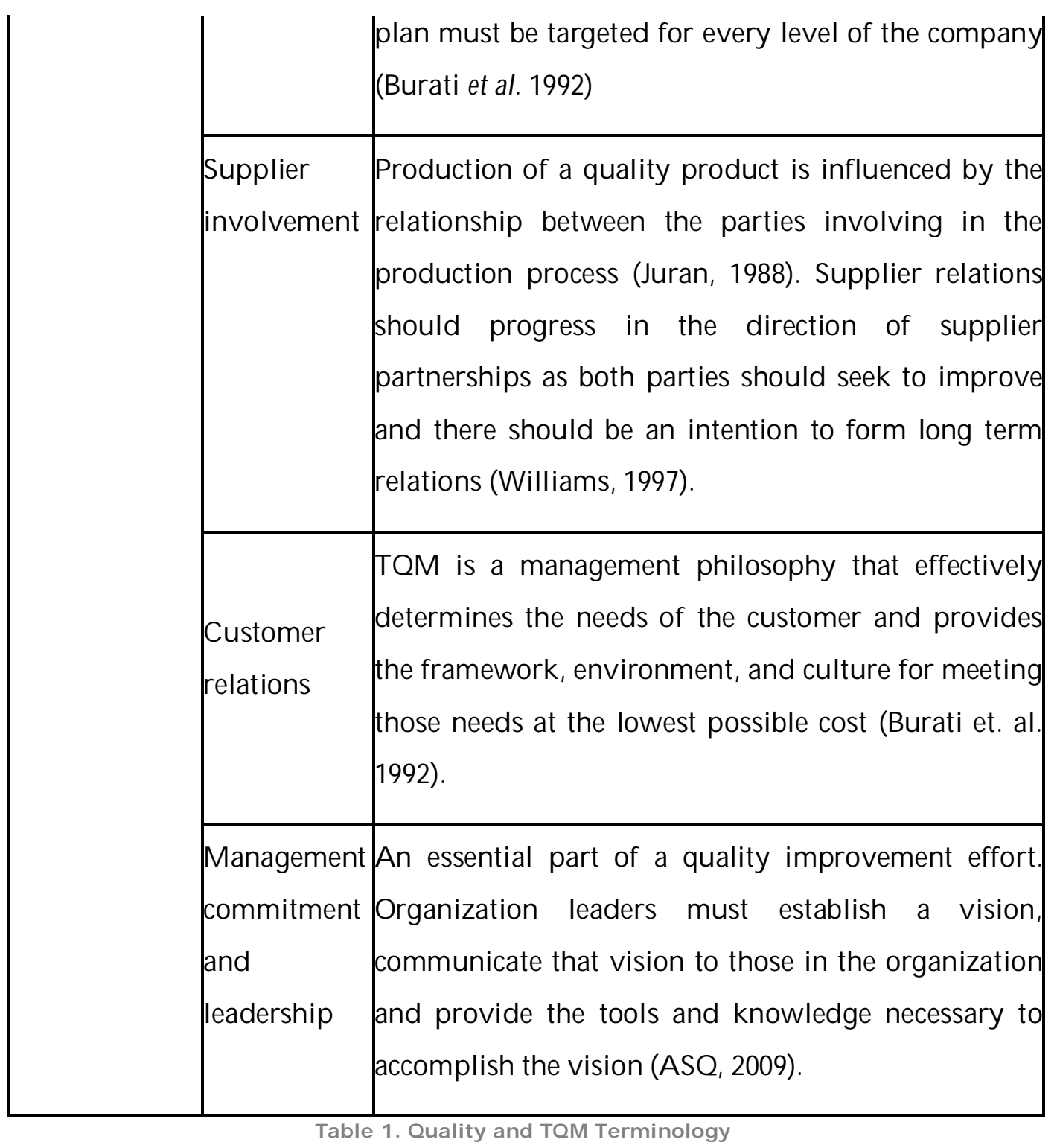

\subsection{RESEARCH DESIGN}

A qualitative research strategy was adopted to understand the quality perception and quality-related attitudes and behaviors of pioneering architecture companies. As part of a multiple-case study, 10 in-depth interviews were conducted with the owner-managers of selected companies located in Istanbul. Most of the owners of these companies have won many prestigious international awards such as the AR Awards for Emerging Architecture, the Europe \& African Property Awards, the Aga Khan Award for Architecture, the Cityscape Architectural Review Awards, and the ULI Award for Excellence and National Building Design Award. The 
sample consists of companies that have been appreciated for their 'high quality' products within the national and/ or international architectural design community.

Data were collected through face-to-face interviews, which lasted for around an hour on average A case study protocol was prepared prior to the data collection phase. Open-ended questions were tested and revised upon a pilot interview. Questions fell into three categories: quality perception, principles and methods adopted to achieve quality, and the company profile. Research goals were clearly explained to the interviewees and the interviews were digitally recorded with the consent of respondents. The researchers paid particular attention during the interviews, to be neutral, empathize with the interviewees, and changed the order of the questions in accordance with the flow of conversations. Including a pilot interview, ten in-depth interviews were conducted in total (see Table 2), however, the pilot interview data were excluded from the analysis. The interviews were transcribed to form an extensive case study database, from which data were then withdrawn for qualitative analysis.

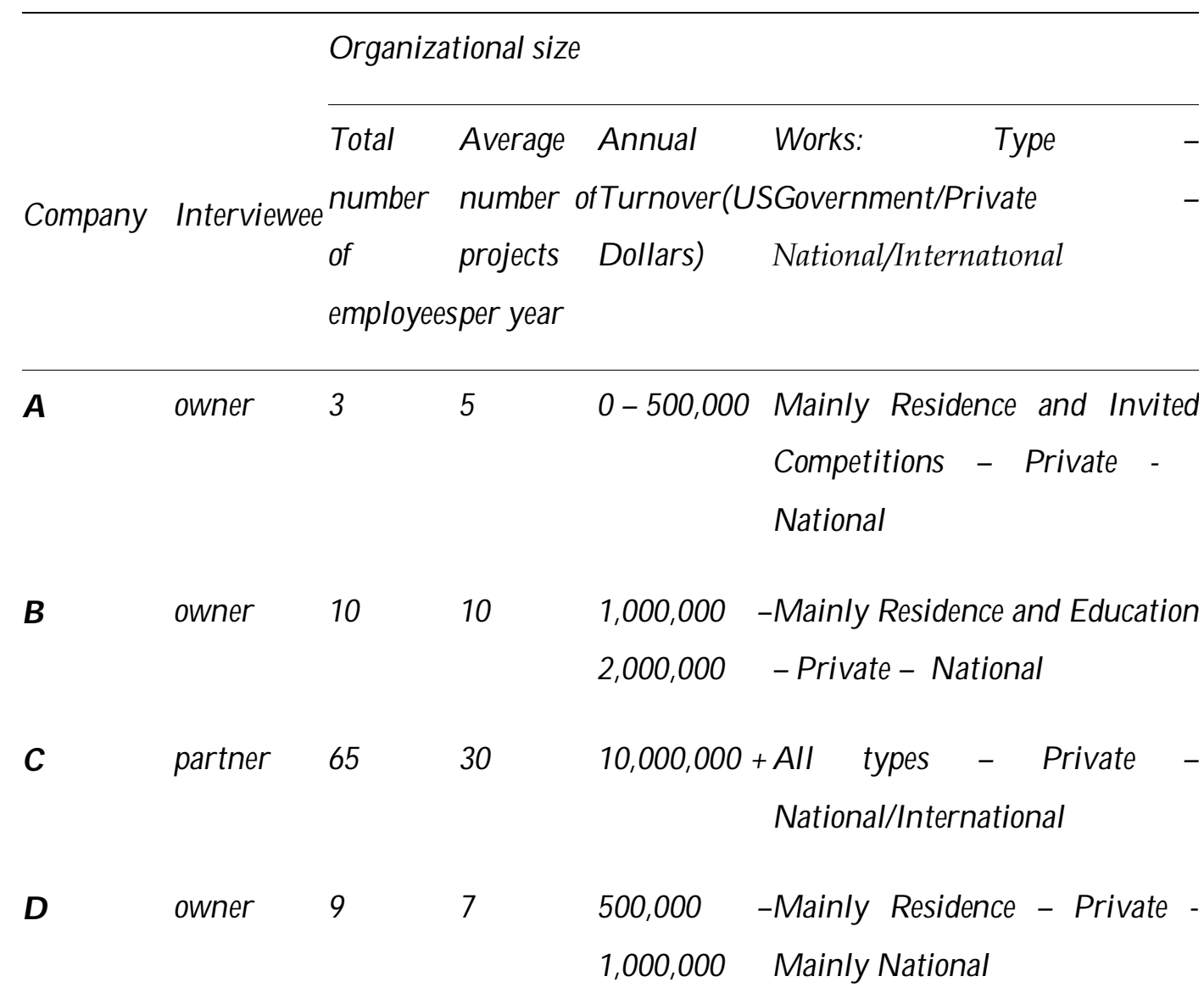




\begin{tabular}{|c|c|c|c|c|c|c|c|c|}
\hline \multirow[t]{3}{*}{$\mathbf{E}$} & partner & 14 & 15 & $2,000,000$ & -M ainly & \multicolumn{3}{|c|}{ Commercial/O ffice } \\
\hline & & & & $5,-000,000$ & Buildings & - & Private & - \\
\hline & & & & & \multicolumn{4}{|c|}{ N ational/International } \\
\hline \multirow[t]{2}{*}{$\mathbf{F}$} & partner & 6 & 6 & 500,000 & \multicolumn{4}{|c|}{-M ainly Office and Education } \\
\hline & & & & $1,000,000$ & \multicolumn{4}{|c|}{ Private - $\mathrm{N}$ ational } \\
\hline \multirow[t]{2}{*}{ G } & partner & 12 & 10 & $1,000,000$ & \multicolumn{4}{|c|}{-All types - Government/Private } \\
\hline & & & & $2,000,000$ & \multicolumn{4}{|l|}{ - N ational } \\
\hline \multirow[t]{2}{*}{ H } & owner & 35 & 25 & $5,000,000$ & types & - & Private & - \\
\hline & & & & $10,000,000$ & \multicolumn{4}{|c|}{ N ational/International } \\
\hline \multirow[t]{2}{*}{ I } & owner & 11 & 20 & $2,000,000$ & -All types & - & Private & - \\
\hline & & & & $5,000,000$ & \multicolumn{4}{|c|}{ National/International } \\
\hline
\end{tabular}

Table 2. Summary of interviews

\section{FI NDI NGS}

\subsection{QUALI TY PERCEPTION}

Interviewees make a distinction between product and process quality and they argue that the quality of the production process does not guarantee the quality of end-product. Subjectivity, which originates from the cultural background of the designer, the relativity of quality perception, and the clients' needs may change the quality of end-product even if all other processes are of high quality.

... there organized competitions, for instance. All participants are given the same topic. M ost of the conditions and the data are the same. However, all come up with different outcomes. In my opinion, all groups achieving quality meet these conditions but they always have a plus which makes a difference. Because the way that they handle the situation is different... But we cannot argue that who puts on more wins because evaluation is subjective. A different jury might make a different decision.

Most interviewees agree on the definition of quality that it is not only 'meeting client expectations, but going beyond those expectations in different and innovative ways': by re-interpreting an element of the client's life from a different 
angle, by intuitively understanding the dients' problems and proposing rapidly the essential solutions or by noticing the missing elements of client's demand with the help of his/ her former experience and making new offers.

Quality includes more than expected. It is something that has never occurred to me, which is really impressive. If it provides me a solution even beyond my expectations, then it really captures me.

\subsection{TEAMWORK AND EMPLOYEE I NVOLVEMENT}

Teamwork is inevitable in architectural design practice as each project is unique and it requires the contribution of different disciplines to implement the project. Interview data suggest that rather than participating in project development directly, owner-managers with propensity to use their leadership skills assign tasks to employees to encourage their participation and to obtain effective consequences out of this participation. They expect all employees to freely render his/ her opinions.

Can you imagine an architect who never tells her/his idea? This drives me crazy. Why she/he is here then?

U ntil quite recently, we used to work like that: we, the owners, were the two opinion generators, of the office... and the employees worked as technicians... As the number of the projects increased, this method lost its validity.

Wherever possible, my starting point is - "tell us how you would do this".

The strategy is often to reach a common mind. As a leader, owner-manager draws the lines and interferes in to make the final decision. Whenever necessary, to prevent such a liberal atmosphere from turning into a chaos, the owner-manager finalizes the decision-making processes in relatively reasonable durations.

... Sometimes, I realize that I loose unnecessarily much time at an unnecessary point of the project waiting for the participation of the employees. Then I have to cut it off.

Interviewees have propensity to delegate their authority as much as possible, as they believe that authority delegation motivates the employees to exert themselves for success. Two approaches are noticeable in authority delegation. One of them is the use of authority delegation as a means of motivation. Employees can be 
delegated authority not only as an appreciation of good performance, but also as a stimulator to improve descending performance and encourage contribution. The other approach is the use of authority as reward, which means that owner-managers delegate authority to those who have al ready proven to be capable of using it and those with relevant competences. Interviewees try to figure out the amount of work that the employee could surmount and the fields that he could be the most effective.

Initiative is given to the ones who can take it, but they should prove having this capacity first. $\mathrm{N}$ othing is taken for granted; they should earn it...

Another perspective on authority delegation is that enthusiasm is more valuable than competence since skills could be improved. Accordingly, concept design, preliminary project, as-built project, site inspections and the relationship with client when possible are carried out by the same person or persons as much as possible. Unlike the former one, this approach suggests that efficiency could be achieved if the same employee keeps working on the subsequent steps. According to this group of interviewees, 'having experience in each phase of the project' is also an effective means of motivation.

... I sometimes fancy as if there are some other tiny offices inside ours... interrelated offices, almost like having an electrical or plant engineer in our projects. Performance of those tiny offices reflects on individuals, and the sum of individual performances reflects on the performance of the office...

However, not always it is not possible to delegate authority in all cases since the leader has also many subjective characteristics that are not easily transferable. This sometimes may even arouse a feeling of being neglected in the employee who strives to conceptualize the elements, the reasons of which she/ he fails to comprehend.

This resembles to doctor-patient relationship. The client comes and indicates a problem, for example. This is the symptom, something apparent. $M$ aybe, the solution he proposes is the pie in the sky. There comes in the intuitions. That's why I cannot share these all with my team. 


\subsection{USE OF STATISTICAL METHODS FOR PERFORMANCE MEASUREMENT}

The regular monitoring of employee performance is considered as a necessity by interviewees since individual performance is closely associated with collective performance. According to some owner-managers, this constitutes an impediment for increasing the number of employees in spite of the existing growth pressure. Although no statistical study could be mentioned, measurements accumulated in the database along with different means of expression are presented to management in periodical meetings.

... all our attempts are for making things measurable and keeping everything measurable.

... employees keep records of the project they work in, the topic they work on and the durations of works... We have a software which keeps record for each consumable material automatically... For instance, each print should be signed, so you can trace, itemize and list the print.

Owner-managers who have less than ten employees tend to carry out performance evaluation on the basis of individual experiences and intuitions without systematically using any performance measurement instruments.

... for this size of an office, I do not administer systematic measurement because I have control on them all... I get up in the morning and revise everything done starting from the beginning...

According to the owner-manager of company B, no reference can be made to 'office performance,' where a large number of people are employed. It is the performance of individuals what makes up the performance of the office in total and thus, it is sufficient to measure individual variables only.

Interview data suggest that performance measurement initiatives broadly fell into thefollowing categories in the architecture companies:

Cost measurements: This type of measurement is carried out in all architectural offices to a certain extent in order to calculate deviations from project budgets and assess profit-loss situation. 'Man-hour' is the most frequently employed 
measurement unit. Another criterion might be the level of resource consumption (i.e., paper, cartridge, telephone calls).

Process measurements: Owner-managers compare the number of proposed projects and completed projects. Durations of the phases following the project proposal and the reasons for delays are also analyzed. Although relatively simple measures such as the ratio of proposed and completed projects are used in most offices, measurement of the phase durations is rare. Data on delays are considered important for continuous improvement.

Individual performance: Owner-managers measure employees' performance in different phases of the projects to "find ways to improve poor performance while rewarding high performance". Though being small in number, there are interviewees who emphasize the importance of the distinction between poor performance as a result of systemic failure and poor performance as a result of individual failure. Owner-managers agree that good performance should be awarded and they explore and use different methods for appreciation. They set various criteria "to be fair and hinder unnecessary competition between employees". Some owner-managers tend to reward unexpectedly high performance, while in some cases company's wage policy is associated with individual performance. In only one case, employees were systematically and regularly given feedback on their performance following an assessment. In other offices, employees were provided performance-related feedback only when there happened a negative incident, or it was in the form an unplanned feedback within the sincere atmosphere of meetings. According to some interviewees, there are some peculiar characteristics of architectural offices in terms of performance measurement. One of them is the variability resulting from the subjective nature of architectural design practice. Another one is the one-off nature of architectural design outputs. In case a project cannot be completed with budgeted costs, it is not easy to compensate this loss since the product is unique like its client/ owner.

\subsection{CONTI NUOUS I MPROVEMENT}

By the very nature of one-off products, each project requires different solutions. To develop tailor-made solutions in each project, companies mobilize all essential 
resources to adapt to the new design problem. All companies have project archives where they keep records of all information related to each project. Knowledge is constantly and cumulatively improved by putting on new information from different project environments, however, interviewees emphasize the traditional importance of oral transmission of knowledge in architectural companies.

I believe that we own a library which is composed of orally transmitted information and which is busier than a physical library. We can handle it now, but I don't think we could, if we were a larger-scale office.

According to interviewees, transforming project-level individual experience into organizational knowledge requires that turnover of experienced employees be kept at minimum. Owner-managers agree that not all know-how related to design practices, however, is easily transferrable. Ability to understand clients' needs and intuitive approaches to design are examples. Standardization of the methods of expression is relatively more easy:

... each piece of paper from this office should arise the same feeling in everyone. For this purpose, a design reference system has been devel oped.

Interviewees believe that technology-based radical improvements should accompany incremental improvements for continuous learning -i.e. the purchase of software or an equipment, which significantly influences the design and modeling processes.

\subsection{TRAI NI NG}

Interviewees acknowledge the importance of training on various topics. Training may take different forms according to different topics: In the case of a general training, invited speakers address various topics that contribute to the individual professional development of employees. Creating sincere atmospheres, where the owner-manager shares his/ her experience on different issues is considered as another form of training. For example, relationships with clients, suppliers and engineering crews or means of earchitectural expression aretypical topics. 
A part from scheduled training sessions, experienced employees are encouraged to transfer know-how to relatively less experienced employees as part of daily problem solving activities.

Relatively more formal forms of training, from which relatively quicker outcomes are expected, focus on various technical issues that are related to ongoing projects. Such training might be arranged within the office or employees might be requested to attend in professional training outside the company. Training on construction systems and equipment is usually arranged with invited speakers from manufacturers or dealers and might focus on various topics that are related to projects. Interviewees believe that visiting trade fairs and field trips are also important channels of learning. Accordingly, employees might be requested to attend in national or international trade fairs, or they might be sent out to see a completed project on site. When they come back, they are expected to share experience with others. Training might also be related to some general topics, without direct link to architectural practice. Finally, all interviewees highlight the need for a well-organized and easily accessible library for individual development.

\subsection{SUPPLI ER I NVOLVEMENT}

Interviewees agree on the importance of early involvement of suppliers with projects and they adopt different strategies for collaboration. Owner-managers argue that due to the very nature of building production processes, design changes and delays frequently happen, and it very important them to work with tolerant and constructive suppliers. Interviewees acknowledge the importance of long-term relations for achieving quality targets, although frequent changes of suppliers are part of business.

\subsection{CUSTOMER RELATIONS}

Architectural practice requires the participation and guidance of clients in each phase of projects. Clients and architects collaborate to identify needs in each step of project development, so that it becomes possible to proceed with the subsequent step. Some interviewees argue, however, that not all of the clients might be acquainted with the idea of working with a designer. Accordingly, the architects often start with explaining how the project is to be proceeded, then go on with 
attempts to understand clients' needs, which typically involves a set of broad questions. Presentation of visuals form previous projects and literature usually helps clients express needs, though the interviewees believe that it is the intuitions of the architect which is fundamental.

When the user is anonymous, the approach to identify clients' needs may differ i.e. in a real estate project, In such projects, the designer is to rely on his own experience to identify needs and take into account an average user profile to ensure the required flexibility. According to interviewees, customer relations is another field where it is difficult to transfer skills to employees.

\subsection{MANAGEMENT COMMI TMENT AND LEADERSHI P}

Most of the interviewees believe that it is a management liability to ensure high quality processes and products. The leader should encourage continuous improvement; set sustainable and improvable standards; provide necessary equipment and comfort; enable teamwork to be carried out effectively in a participation and dialog-oriented atmosphere, and meet employee satisfaction. $\mathrm{He}$ she should act as a role model and inspire employees to behave like professionals.

All interviewees appear to appreciate a management style, which is based on authority delegation and which encourages employee participation. .

We have realized that if they take responsibility and actively participate in the conceptualization phase as much as possible, then we are likely to achieve better progress...

\section{DI SCUSSI ON AND CONCLUSI ON}

Findings from the analysis of qualitative research data suggest that various practices, which are targeted at achieving high quality products and processes as part of professional practice in architectural offices overlap in many aspects with the principles and applications of Total Quality Management (TQM), though those principles and applications are not systematically described as TQM. Empirical data present strong evidence that various aspects of TQM have already been integral to the daily routines of architectural practice. To illustrate, each project is 
unique in terms of technical problem solving and this is a motivation for continuous improvement; various forms of formal and informal training are adopted by companies, where oral transmission of know-how is a strong tradition; close and strong relationship with client is part of business because of the very nature of professional practice; unlike many other sectors, the designer and his client (and the user) mostly know each other at the beginning of the process, owner-manager is very much expected to demonstrate high leadership skills, as typical of small companies...Thus, it might be safe to arrive at a conclusion that architectural design offices already adopt various strategies to arrive at quality targets, the sophistication degree of which vary with the specific needs of each organization. There are signs that architecture companies adopt a pragmatic approach and they tend to employ relatively more 'professional' methods to establish quality systems, only when they actually need them (i.e., to manage human resources when the organizational size grows).

Another conclusion from this study is that the specific characteristics of architectural business should be taken into account when developing any kind of quality management models. The dilemma is that although TQM and other management approaches require that processes and products be standardized as much as possible, the very nature of design practice does not allow the standardization of every aspect of business. Difficulty to transfer particular skills (i.e., the creative technical problem solving skills or the ability to understand and foresee client/ user needs) and the traditional emphasis placed on learning-bydoing under the management of a skillful leader, where oral transmission of knowhow is important, among others, are some of the peculiar characteristics of architectural design practice.

Translating the findings of this study into a manageable model of quality management for architectural design offices through a quantitative research and exploring linkage between organizational culture and quality-related initiatives in architectural practice would be interesting topics for future work. Further research could also focus on in-depth case studies of the various dimensions of quality (i.e., teamwork, training, statistical methods, etc.) for building design process. One might also analyze the best practices of quality improvement tools for the design 
process. As the complexity of the buildings increase, further research efforts to provide high quality design services are sine-qua-non.

\section{REFERENCES}

ARDITI, D. and GUNAYDIN, H.M. (1997). Total Quality Management in the Construction Process. International Journal of Project Management, 15: 235-243.

ARDITI, D. and GUNAYDIN, H.M. (1998). Factors That Affect Process Quality in The Life Cycle of Building Projects. Journal of Construction Engineering and Management, 124: 194-203.

ASQ (2009) http://www.asq.org/glossary/q.html (accessed 18-Dec-09).

BURATI J. L. Jr., MATTHEWS M. F. and Kalidindi S.N. (1992) Quality Management Organizations and Techniques. Journal of Construction Engineering and Management, 118: 112-128.

BURATI J.L. Jr. and OSWALD T.H (1993). Implementing TQM in Engineering and Construction. J ournal of Management in Engineering, 9: 456-470.

JURAN, J.M. and GRYNA, F.M. (Ed.) (1988). Juran's quality control handbook. New York: McGraw-Hill, Inc.

MASAAKI I. (1986). Kaizen, the key to Japan's competitive success. New York: McGraw-Hill Publishing Company.

MAYON-WHITE B. and MABEY C. (1993) Managing Change - 2Rev. ed. London: Paul Chapman Publishing Ltd. Page (88).

MOHR-JACKSON I. (1998) Managing a Total Quality orientation: Factors Affecting Customer Satisfaction. Industrial Marketing Management, 27: 109-125.

OAKLAND J. S. and ALDRIDGE A. J., Quality Management in Civil and Structural Engineering Consulting. International Journal of Quality \& Reliability Management 12: 32-48.

PERISCO, J., J r., Team up for quality improvement. Quality Progress, 1989, 22(1), 33-37.

PHENG L. S. and KE-WEI P. (1996). A Framework for Implementing TQM in Construction. The TQM Magazine 8: 39-46.

PHENG L.S. and TEO J.A. (2004). Imlementing Total quality Management in Construction Firms. J ounal of Management in Engineering, 20: 8-15.

PRICE A. D. F., BRYMAN A. and Dainty A. R. J. Empowerment As a Strategy for Improving Construction Performance. Leadership and Management in Engineering, 4: 27-37.

PSYCHOGIOS A. G. and PRIPORAS C. V., Understanding Total Quality Management in Context: Qualitative Research on Managers' Awareness of TQM Aspects in the Greek Service Industry. The Qualitative Report 12: 40-66.

VOLKER, L.and PRINS, M. Exploring the possibilities of correlating management with value in architectural design. Proceedings of CIB W096 Architectural Management. Lyngby, Denmark, 2005.

WILLIAMS N. (1997) ISO 9000 as a route to total quality management in small- to medium-sized enterprises: Snake or ladder?. The TQM Magazine, 9: 8-13.

YILDIRIM, A. and SIMSEK, H. (2000) Sosyal Bilimlerde Nitel Araştırma Yöntemleri. Ankara: Seçkin Yayıncılık Ticaret A.Ş. 
